\title{
Assessment of a novel technology for a stratified hot water energy storage -The Water Snake
}

\author{
Amin Al-Habaibeh ${ }^{\mathrm{a}}$, Bubaker Shakmak ${ }^{\mathrm{a}}$, Simon Fanshawe, \\ ${ }^{a}$ Innovative and Sustainable Built Environment Technologies (iSBET), School of Architecture, Design and the Built Environment, \\ Nottingham Trent University, NG1 4BU, UK \\ Amin.Al-Habaibeh@ntu.ac.uk; bubaker.shakmak2016@my.ntu.ac.uk \\ ${ }^{b}$ Gannet Limited, Nottingham, UK; simon@gannet.co.uk
}

\begin{abstract}
The increasing demand to enhance sustainability and reduce carbon emission and pollution is attracting the attention for implementing and integrating diverse heating technologies such as heat pumps, solar energy, gas boilers, Combined Heat and Power (CHP), and electric heaters. Integrated technologies for heating include low and high temperature district heating, domestic small-scale applications and commercial largescale buildings. Energy from flooded coalmines and water from other sources could also play a vital role in improving energy efficiency of heating and cooling applications. Stratified thermal storage are likely to significantly contribute to energy efficient heating, particularly when implementing a mixed-approach of diverse technologies. A stratified hot water tank, and naturally stratified reservoirs, are expected to play a central role in the integration of several heating technologies that operate efficiently at different levels of temperature with reduced cost. This paper presents a new innovative technology to improve stratification, namely 'the water snake', and an automated test rig to evaluate the new stratification method for energy utilisation using energy storage of hot water. An automated system is utilised to evaluate the performance. The results indicate that the test rig has been successful for the automated testing of the technology. Moreover, the results show that the water snake, as a new technology for stratification, is successful in minimising mixing and turbulence inside the thermal energy storage. The results prove that the technology could be implemented for a wide range of applications to enhance the efficiency of heating systems in buildings as well as district heating and cooling applications.
\end{abstract}

Keywords: Stratification; Water snake; Hot water storage; Thermal energy storage; Heat pumps; District heating.

\section{Nomenclature}

CHP: $\quad$ Combined Heat and Power.

TES: $\quad$ Thermal Energy Storage.

$\mathrm{CO}_{2}$ : $\quad$ Carbon Dioxide.

COP: $\quad$ Coefficient Of Performance.

MDPE: Medium-density polyethylene.

${ }^{*}$ Corresponding author. Tel.: +44 (0) 115848 2564; fax: +44 (0) 1158486166.

E-mail address: Amin.Al-Habaibeh@ntu.ac.uk 
UVR1611: Universal controllers

PT1000: $\quad$ Platinum Resistance Thermometer Sensor.

DHW: $\quad$ Domestic Hot Water storage.

\section{INTRODUCTION}

In recent decades, the world has increasingly become interested in the production of electricity and energy from renewable energy. As a result, the world is facing the problem of storing energy for later use because of the instability and discontinuousness of renewable energy resources due to variations in location, weather and season [1]. Since the energy can be converted to other forms, it would be possible to store it for later use [2]. Several storage methods have been created in research and industry such as magnetic systems, electrochemical systems, hydro systems, pneumatic systems, mechanical systems and thermal systems [3]. Thermal Energy Storage (TES), which could use water, oil and molten salt, is a technology used to store the thermal energy for later time use in buildings and industrial processes [4], [5]. Water is considered to be the simplest and most suitable heat transfer and heat storage fluid because of its high volumetric heat capacity, low cost and widespread availability [6], [7]. Hot water storage is used in almost every home to provide a reliable source of hot water [8]. Technologies that use water are common in heating and cooling applications as well as power generation. TES systems can assist in balancing energy demand and supply; reducing peak demand, energy consumption, $\mathrm{CO}_{2}$ emissions as well as cost [9]. A thermal energy storage provides a focus point for heating systems, allowing several producers of heat to contribute to the heating system and several consumers to draw from it. This allows adventitious sources such as solar thermal to be used with the greatest flexibility. It also simplifies the control required as the store use need to be kept at a minimum temperature as is required to meet the demand. Where some or all of the heat required for a building is produced by electricity, the thermal energy storage allows heat to be generated at times of high availability, stored and used when required. This has advantages for both the consumer who will see reduced bills and the grid which can reduce peak demand spikes and reduce emissions arising from having to generate inefficiently to cover the requirement.

\subsection{Thermal storage systems}

Thermal storage systems are already widely used with solar thermal systems so that the heat can be used after sunset. Thermal storage systems are used to reduce the mismatch between the supply and the demand of power [10]. Thermal storage systems such as Domestic Hot Water storage (DHW) is mandatory when solar system is used in heating up water [11]. Thermal storage systems are also used for heat pumps and boilers. Thermal storages are an attractive option to use because of their simplicity and low cost [12]. They can be used to enhance the hot or cold storage buffer tank and also they can be used to enhance the stratification of the water in flooded coalmines to reduce underground water mixing between the water intake and return [13], [14]. Hence, there is an increasing 
market for large stratified thermal storage systems as they allow inputs from different heat sources to be combined and used for heating and hot water inside the property.

\subsection{The Stratification Process}

The term 'Stratification' refers to the intention to heat, or cool, two or more horizontal layers to different temperatures. In a stratified water storage tanks, the hot water lies above the cold water to form a gradient thin layer called thermocline [15]. Typically, the lower $60 \%$ of a thermal store is heated to an appropriate temperature for space heating with the top $40 \%$ being at a temperature high enough for the hot water preparation. The less mixing there is between fluids at different temperatures, the more efficient the stratification is.

The stratification is one of the ways utilised to improve the performance of solar water heating systems [16], [17]. It is one of the main factors of the performance of the hot water storages. It is the degree of the difference in temperatures between the top and the bottom parts of water inside the collector [18]. Stratification is found to be efficient not only for the water storage tank but also for the whole system linked to it. For example, for a solar collector, it has been found that the thermal stratification decreases the temperature at the collector inlet which increases its efficiency as well as it decreases the operation cycle of the secondary source of energy [19]-[21]. The stratification is becoming an effective factor for both commercial and environmental reasons. Stratified tank will keep the hot water for longer periods and hence reduces the heating and reheating processes, which are normally costly and wasteful to the environment. Thermal stratification leads to higher operation temperatures, lower auxiliary energy consumption and higher exergy outputs [22],

Several parameters influence thermal stratification such as the tank geometry, inlet, outlet and operating conditions [7], [23]. The location of the inlet is one the most important factors that affects the stratification of the tank. The design of the inlet is found to have more impact on the tank stratification [24]. This means that the inlet fluid should be entered to a suitable height [25]. Therefore, the methods that improve the supplying process of the water to the right level inside the thermal storage is vital. Existing systems use different designs of inlet stratifiers such as vertical polymer pipes with openings along their heights and porous tube manifolds [24], [26], vertical fabric pipes and vertical polymer film pipes with openings in different levels [27].

The benefits of a stratified store have been appreciated for some time. The advent of heat pumps and solar thermal greatly increases the benefits from stratification. It is now entirely realistic for half the calorific value of gas consumed in a power station to appear as electricity entering a building. Air source heat pumps, properly installed, can operate at COPs in excess of 3 giving an immediate advantage over gas fired heating. The COP of a heat pump is directly related to the temperature at which the heat is generated. A good 
stratified thermal store can significantly increase the average COP of a heat pump.

\subsection{The water snake}

One of the novel methods proposed to improve the stratification inside the thermal energy storage is by using a thin flexible tube, named as the water snake [28]. The water snake moves up and down according to the temperature and the density of water entered into the tank placing it in the right layer where temperatures and densities are the same. Furthermore, the technology could also be implemented on a larger scale for open loop geothermal heating and cooling systems using water from flooded coalmines and large water reservoirs as energy storage buffers [13], [14]. This means the water snake could be implemented to reduce mixing in temperature between the water inlet and outlet, hence improving the efficiency of the system.

Early hot water storage tanks had a high degree of mixing and therefore they had a uniform temperature, however, in recent years, they are being designed to keep a higher degree of stratification as much as possible [29]. Existing designs for stratified thermal stores rely on fixed baffles, chambers and other features to reduce the turbulence as fluid returns to the store. This means that, inevitably, mixing of fluid at different temperatures will occur and the result is not perfect. The novel Water Snakes of this paper offer the following advantages:

- $\quad$ Because they direct the entire flow to the layer at the same temperature it is hard to conceive of a design that could be more thermodynamically efficient.

- $\quad$ The design is inexpensive, simple, reliable and requires no separate control.

- The method is effective enough to avoid the need to get the fluid in at "approximately" the right level. This reduces the need for zone valves and controls

The novel approach of the water snake contributes to saving energy by maintaining low level of increase in entropy generation levels. In other word, the efficiency of the heat pumps and solar thermal heat generation will be improved if the entropy generation is kept to a minimum. 


\subsection{The water snake concept}

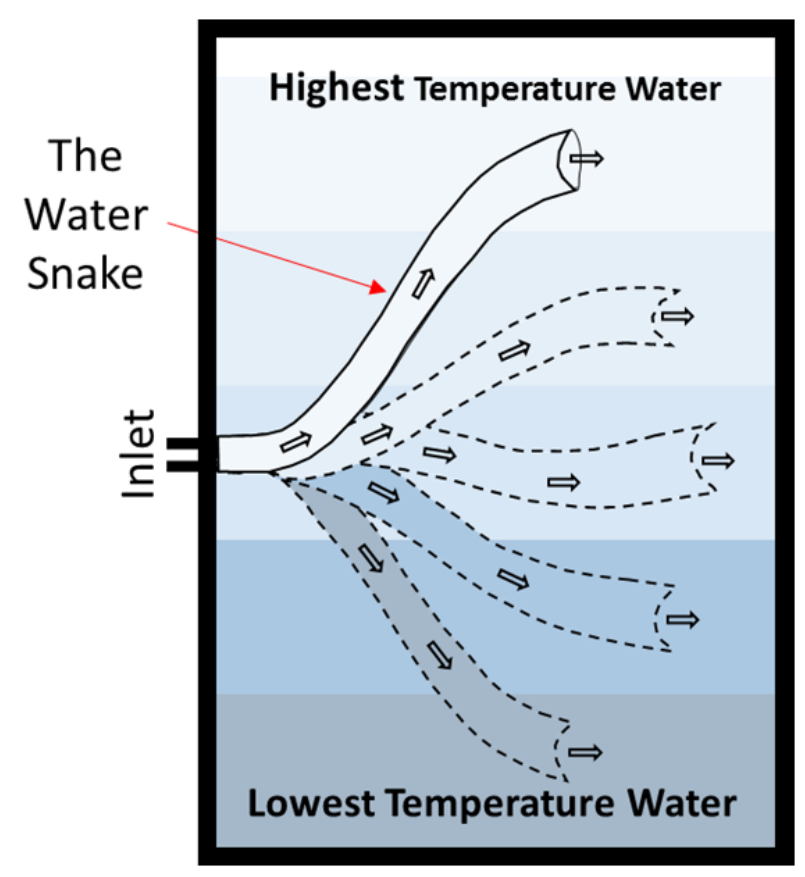

Fig. 1. A schematic diagram that shows the movement of the water snake to the proper water layer that match the inlet water temperature.

The water snake is a radically new method for minimising mixing and turbulence of water entering a stratified thermal store. It is a highly flexible thin walled tube which is fixed and sealed to the feeding line into the vessel. The open end is free to float within the vessel such that it will rise or drop to a position of neutral buoyancy. Thus, the end of the snake will move to the right temperature level equal to the temperature of water flowing in the snake hence reducing any mixing between different temperature levels [28]. Fig. 1 outlines the basic principle of the water snake movement inside a thermal tank. The water snake will move to the proper layer of water that its temperature and density identical to the temperature and the density of the supplied water. The water snake is connected to the inlet pipe with its other end left open and free to float within the vessel such that it will rise or drop to a position of neutral buoyancy as shown in Fig. 1. The water snake inlet point is preferred to be in the middle point so that the water snake can lead the inlet water to its right layer in less time as well as its length will be reduced to the minimum value that can reach both top and bottom layers.

Fig. 2-a shows a thermal store (2) with several ports (7) which may be inlets or outlets. A single water snake is shown for clarity although, typically, there would be several inlets and thus several similar snakes. A fixed inlet port (1) allows the fluid to flow into the thermal store. The water snake (8) is sealed to the inlet port (1) by means of a seal (3) inside the thermal store. This forces the flow to pass down the snake to the end (4) which is floating freely within the body of fluid inside the store (9). The end (4) will settle in the 
layer where the densities, and therefore, the temperatures, are the same. Where the snake is passing through layers at different temperatures, it will tend to be vertical. The portion of the snake between the inlet point and the layer at the correct temperature will tend to collapse to the point where drag caused by the flow through the snake balances the pressure difference between the inflow and that in the body of the vessel.
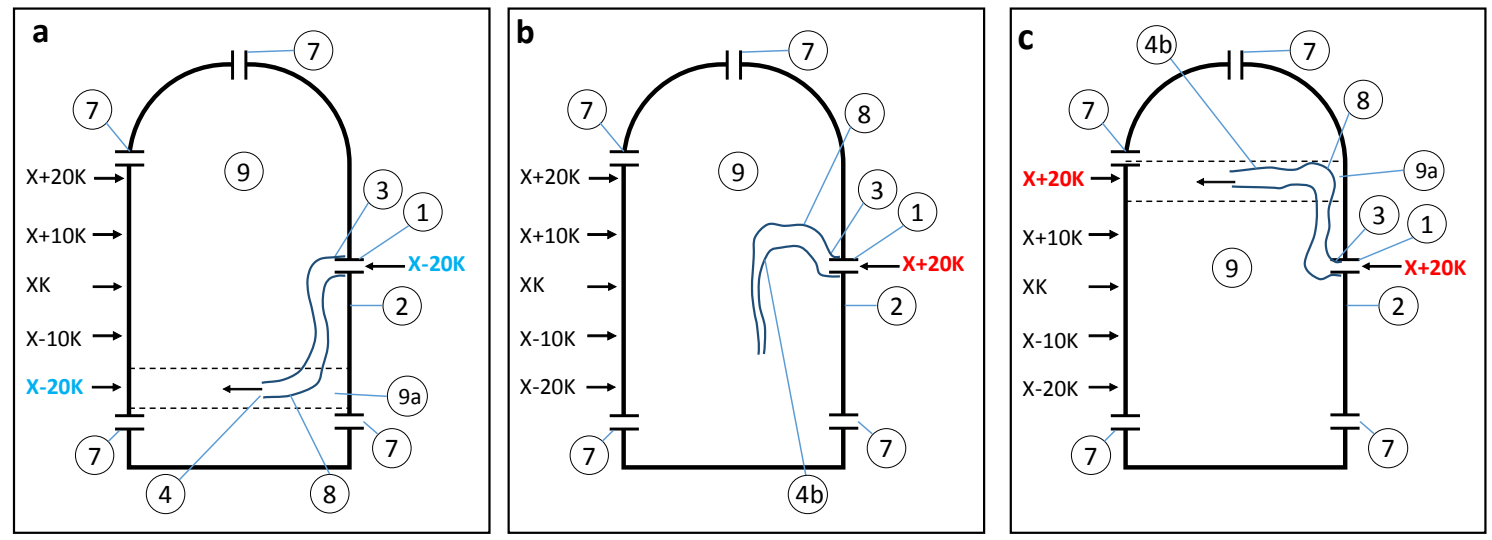

Fig. 2. A schematic diagram that shows the snake at low level when cold water is supplied (a), the initial reaction of the snake when hot water is supplied (b) and the snake when settles in the hot water layer (c).

To the left of Fig. 2-a of the thermal store are figures indicating the temperature of the fluid in kelvin expressed in relation to the temperature at the centre of the store, denoted " $X$ " kelvin. Fluid is entering the thermal store through that port at $X-20 \mathrm{~K}$ and everything is stable. Because the density of the fluid is higher than that of the fluid in the body of the store (9) at the level of the inlet port (1), the fluid entering the snake drops and takes the snake (8) with it. When it reaches the lower layer (9a) (between the dotted lines) there is no longer a downward force on it as the temperatures and thus, the densities are in balance. Here the flow will try to spread out horizontally until it passes out of the end (4) to join the fluid in the vessel. In this example the snake (8) has a uniform cross section throughout its length, except for where it is attached to the inlet port (3). The correct cross section is obtained by balancing the effect of having it too small resulting in a high fluid exit velocity out of the end (4) causing turbulence and too large a cross section increasing thermal transfer through the wall of the snake (8).

Fig. 2-b illustrates what happens when the temperature of the fluid entering the water snake has just increased from $X-20 \mathrm{~K}$ to $X+20 \mathrm{~K}$. The lower density fluid entering the snake (8) collects near the inlet (1) and begins to rise whilst the colder denser fluid near the outlet drains out and the free end of the snake (4b) closes and is pulled up by the hotter fluid. 
Fig. 2-c illustrates what happens when hotter fluid flow has reached the outlet and stabilised such that the snake (8) is lifted up and the outlet (4c) stabilised at the temperature strata (9c) consistent with hotter flow.

\section{THE EXPERIMENT WORK}

This section will discuss the full details of the experimental work including the structure of automated test rig and the condition monitoring system and control system utilised to run the experiments.

Fig. 3 presents a schematic diagram of the automated experimental test rig developed to evaluate the new technology (the water snake) for stratified hot water, as configured for the first run of the machine. Further circuits could also be added to simulate space heating and domestic hot water preparation using a plate heat exchanger. These will both include a water snake to return water into the tank. The technology could also be used to enhance stratification in open loop systems for using water from flooded coalmines and underground reservoirs with heat pumps for heating and cooling applications.

\subsection{The experimental work setup}

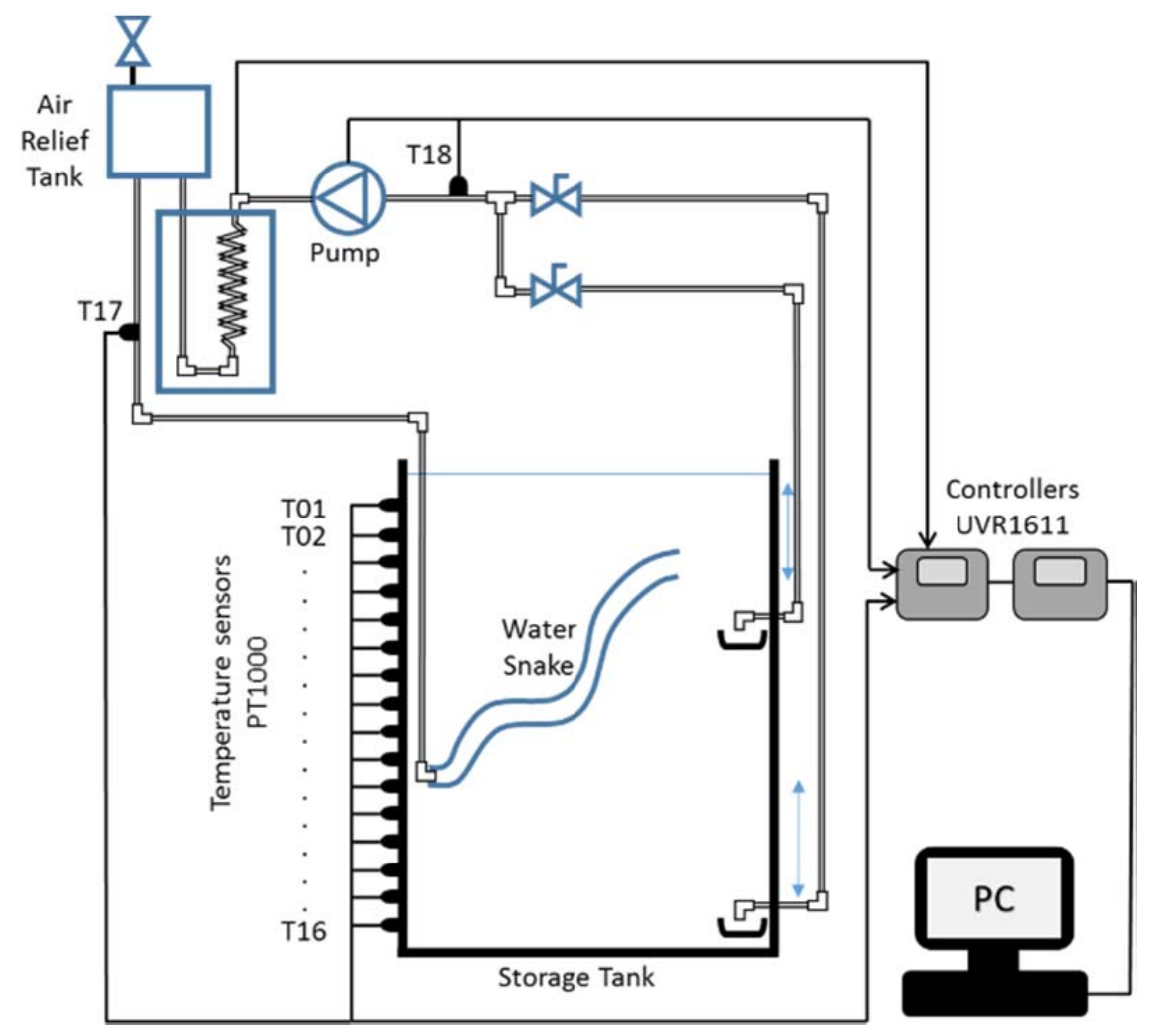

Fig. 3. The schematic diagram of the automated experimental test rig 
The automated test rig is programmed to circulate the water from/to the water storage tank. The water will be drawn as required from any level of water within the tank. The drawn water will be either heated up using the heater coil or introduced without heating and then returned to the tank to investigate whether the new technology of using the water snake can feed the inlet water to the exact layer of water inside the tank. Fig. 4 shows an actual water snake in two positions. The end open of the water snake moved to the layer of water that have the same density and temperature of the supplied water.

Evaluation of the stratification process inside the TES is carried out using either density approach or temperature approach [30]. In this paper, for the evaluation of the stratification and consequently the performance of the water snake as a novel technology, the temperature approach is used. Therefore, a multiple temperature sensors have been located in the left side of the tank to probe the temperature of layers of water up to sixteen layers.

a

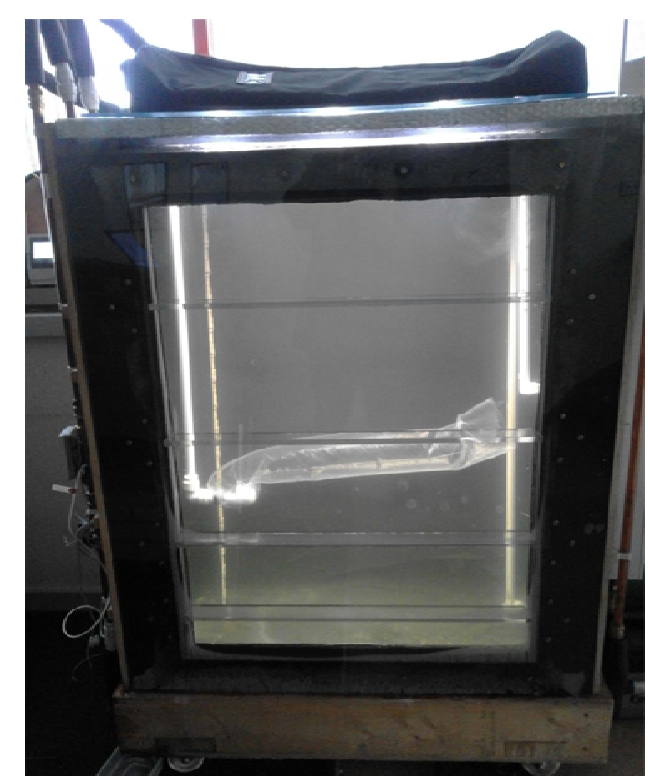

b

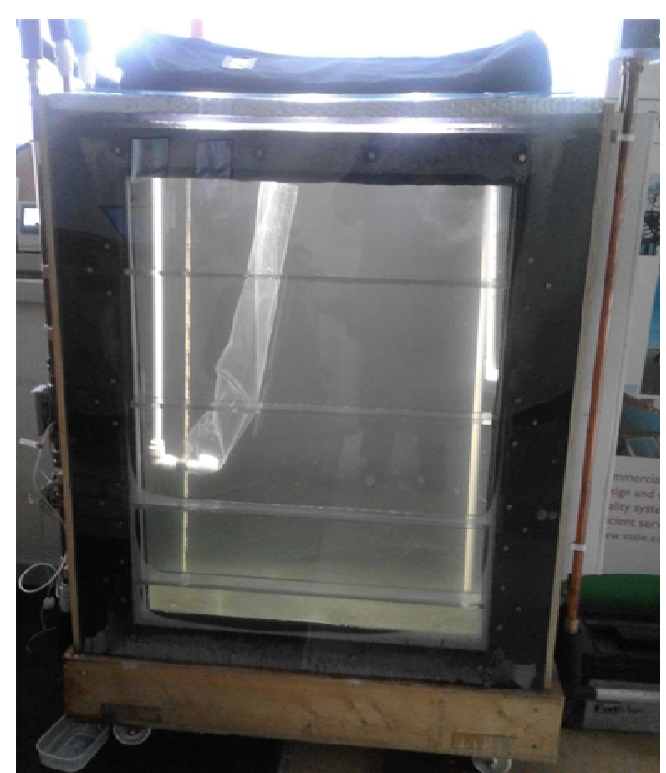

Fig. 4. The snake in the middle position where water from the bottom of the tank is heated to a temperature equal to that in the middle portion of the tank (a) ; and the snake in the top position when the top layer was being heated such that the returning water was hotter than that at the top of the tank (b).

\subsection{The Water Snake}

The Water Snake consisted of a flexible tube of length of $760 \mathrm{~mm}$ and diameter of 100 $\mathrm{mm}$ and thickness of $0.05 \mathrm{~mm}$ polyethylene lay flat tubing. The snake as shown in Fig. 5 is connected to the inlet point from one side and the other side left free. One of the purposes of the automated test rig is to test different materials and dimensions to optimise the effectiveness of the technology. 


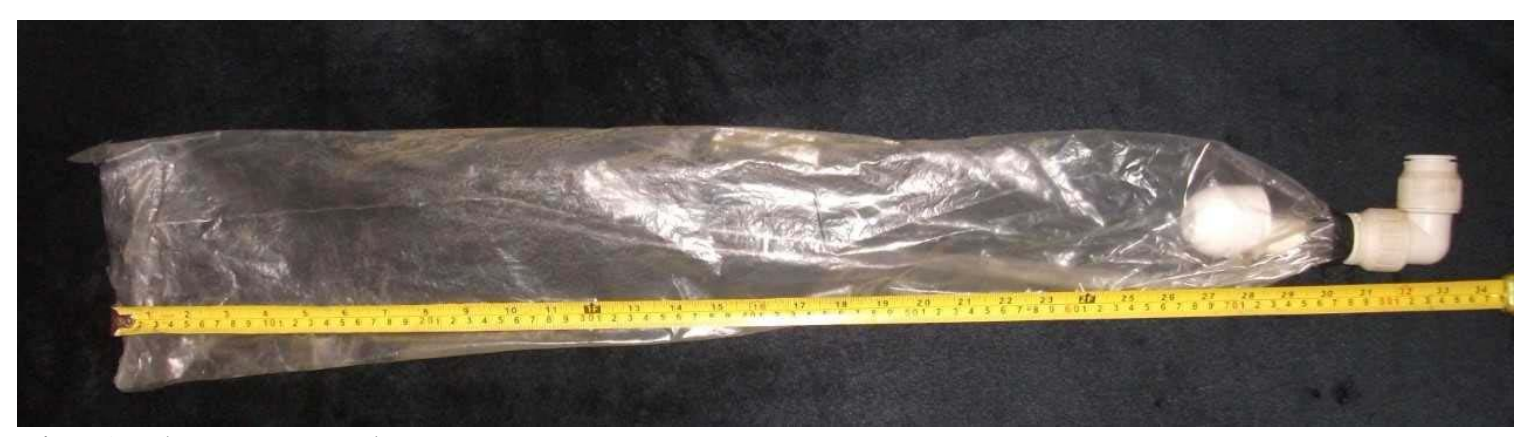

Fig. 5: The water snake

\subsection{Water flow through the water snake:}

Mass flow rate or velocity of water is the major contributor to generate turbulence which may cause the water snake to become impractical. A key feature of the snake is that it needs something at the inlet point to absorb the kinetic energy such that the flow through the snake is reasonably uniform. The experimental test tank has been provided with a device that reduces the water speed and creates a laminar flow. The flow was measured at $0.85 \mathrm{~m} 3 / \mathrm{hr}$ and remained fairly consistent throughout the test.

The influence of the flow on the performance of the water snake will be taken in consideration in future work.

\subsection{The Water Storage Tank}

To reduce the cost of the system a 650l upright Medium-density polyethylene (MDPE) water tank is used in this work, see Fig. 6-a. The plastic tank is modified to create a double-layered transparent front window to monitor and video the water snake. Due to the high temperature involved, a wooden structure was designed to give the plastic tank the necessary mechanical support and insulation. The tank is filled to a depth of about 1,130 $\mathrm{mm}$ with cold water. This went up by about $20 \mathrm{~mm}$ during the test due to thermal expansion.

\subsection{The Automated Experimental Rig}

The experimental test rig comprises a hot water storage tank with clear polycarbonate window, pump, pipes, control system based around UVR1611 controllers, electric boiler, temperature sensors, and the Water Snake, see Fig. 6-a.

\subsection{The controllers (UVR1611)}

The control system for the test rig implemented two UVR1611 universal controllers coupled with a data logger. See Fig. 6-b. 


\subsection{The PT1000 Sensors}

The PT1000-sensor is used for accurate temperature monitoring applications. It is simple to use in many applications because of its simple linear relationship of the resistor and temperature. It is widely used in industrial application for temperature monitoring, control, and switching. It has a resistance change of $3.1 \mathrm{Ohm}$ per $1{ }^{\circ} \mathrm{C}$ with error of 0.02 ${ }^{\circ} \mathrm{C}$.

Two PT1000 sensors are implemented to measure the flow through the electric boiler using standard pipe sensors. Sixteen PT1000 sensors sealed to a glass fibre rod are used to measure the temperatures in the tank. The lowest sensor (T16) is roughly $40 \mathrm{~mm}$ from the bottom of the tank. The sensors are spaced at $70 \mathrm{~mm}$ intervals with the top one (T1) at $1,090 \mathrm{~mm}$.
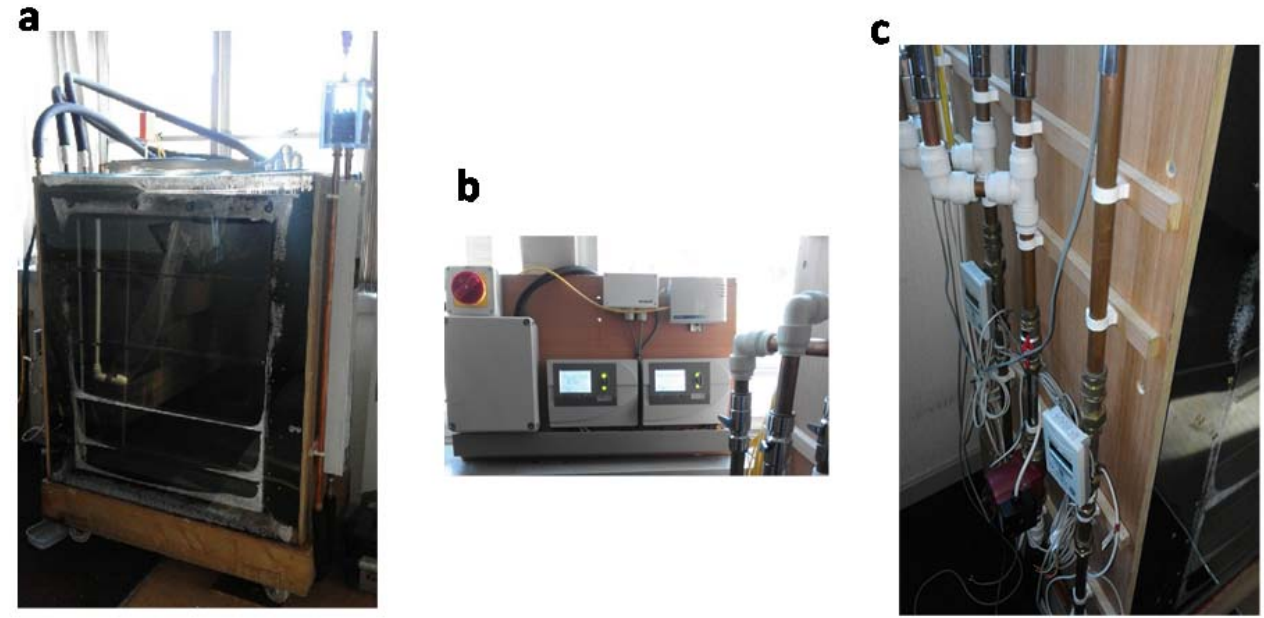

Fig. 6. The automated test rig (a), the two UVR1611 controllers (b) and pipes and instrumentations work (c).

The first UVR1611 controls the circulating pump and four 3kW stages in the electric boiler. This also measures the temperatures of the water being drawn from the tank (T18) and the heated water being returned through the water Snake (T17). The temperatures in the tank are measured by sixteen PT1000 sensors connected to the 2nd UVR1611 (T1 to T16). Each has only 16 inputs so it has been necessary to use two controllers. In the present test only the plumbing required for heating the tank is present and the valves used to select one of the two levels to draw out the water are chosen manually. The first initial preparation test is primarily intended to demonstrate the test rig and to heat it above its range of expected working temperatures, $20^{\circ} \mathrm{C}$ to $80^{\circ} \mathrm{C}$. The fluid in the tank is fresh water with some corrosion inhibitor added. As the water had not been previously heated, some air bubbles came out of solution and this lifted the snake above the target level during part of the test. The air bubbles disappeared and the water snake worked perfectly. 
Nevertheless, a reasonable degree of stratification has been achieved under the circumstances.

\section{RESULTS}

\subsection{Initial condition}

Multiple experiments have been carried out to investigate the multiple scenarios of the water snake. In each experiment, there have been several trials in which either cold or hot water is pumped into the tank several times. Fig. 9 shows the real water snake in multiple levels when water at different temperatures has been injected to the tank at the inlet. The inlet water is circulated from/to the tank by changing the position of the outlet point. When a hot water is needed, the outlet point is raised up while, when a cold water is needed the point is lowered down. This can be seen in Fig. 10 and Fig. 11 where the blue lines represent the movement of the water snake up and down. In some cases, the inlet water is heated up by an external heating element to represent an external heating source. Fig. 11 shows the results of one experiment which has continued for one hour. The figure shows clearly how the tank is not well stratified at the beginning of the experiment and then how it becomes clearly stratified even though different water with different temperatures have been inject to the tank in random order.

\subsection{Water Snake movement detection (Matlab Code)}

Following the experimental work, the data collected from multiple experiments have been processed using Matlab software. A Matlab intelligent image processing code has been developed to detect the movement of the water snake from the videos that have been recorded during the experiments. The code is especially programmed and developed by the authors for this purpose. The code is built based on image processing techniques. The Matlab software is also used to analyse the data and to plot the graphs and the images of the tank.

\subsection{The initial state}

Fig. 7 shows the temperature measured vertically along the tank using the sixteen temperature sensors equally spaced along a vertical probe immersed in the tank. Fig. 7 is for the temperature measured prior the use of the water snake. The temperature sensors as shown in the figure are representing the y-axis while the x-axis is showing the time in seconds. Prior to the use of the water snake there has been no real stratification in the tank and the stored water has been dominated by the temperature of the injected water. The difference in the stored water temperature is small between the top and the bottom. The measured temperature in the tank prior the use of the water snake has been found ranging between $50{ }^{\circ} \mathrm{C}$ and $60{ }^{\circ} \mathrm{C}$. 


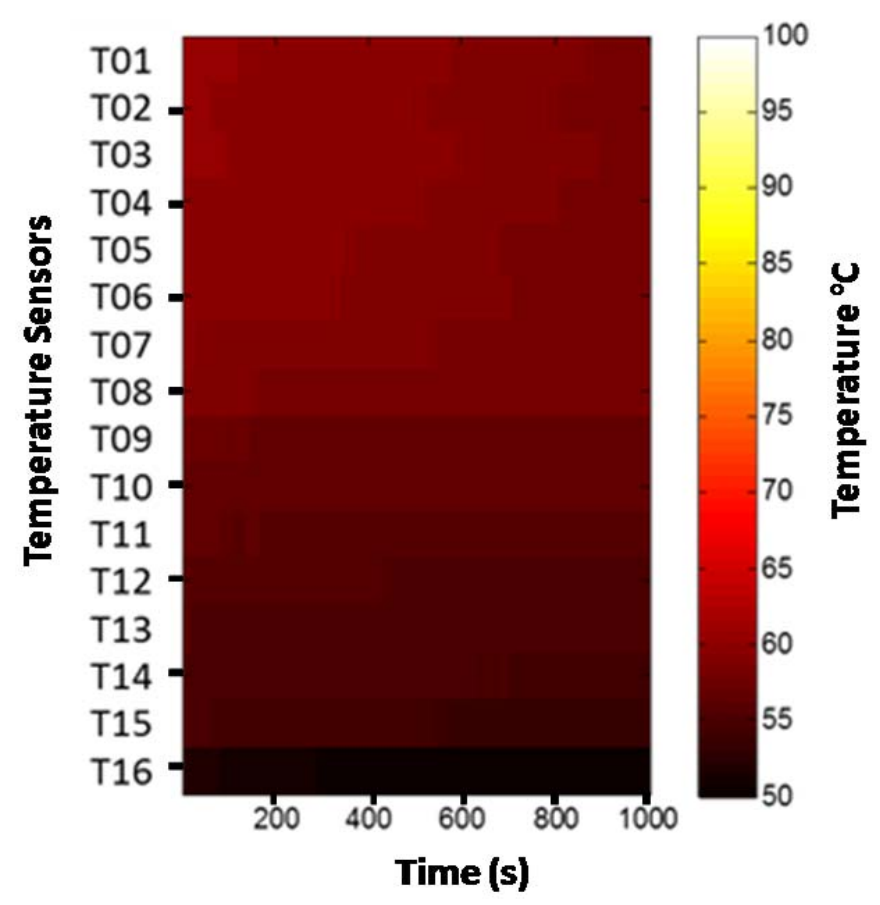

Fig. 7. The poor stratification process without the water snake.

\subsection{Difference between stratified and non-stratified tank}

When hot or cold water is supplied to a tank without using the water snake the temperature of the supplied water will dominate the tank. It can be seen clearly in Fig. 8 that when we supply either hot water or cold water without using the water snake, the supplied water will substantially dominate the whole temperature of the water inside the storage tank. As it could be seen from the figure, the temperature across the tank did not differ much when the water snake is not used. Line B in the figure shows how the temperature along the tank is not significantly changing as measured by the sixteen sensors when the colder water is injected and dominated the stored water. Similarly line C shows the temperature along the tank when a hotter water is injected to the tank and dominated the whole tank temperature. Both lines B and C show small difference between the top sensor (T01) and the bottom sensor (T16). While when the snake is used, the hot water moved to the top of the tank without being mixed with the cold water and the cold water moved to the bottom of the tank without being mixed with the hot water. At the end, we had a perfect stratified water storage tank. This can be seen clearly in the Fig. 8 line A, where we have a big difference in temperature between the top sensor (T01) and the bottom sensor (T16). 


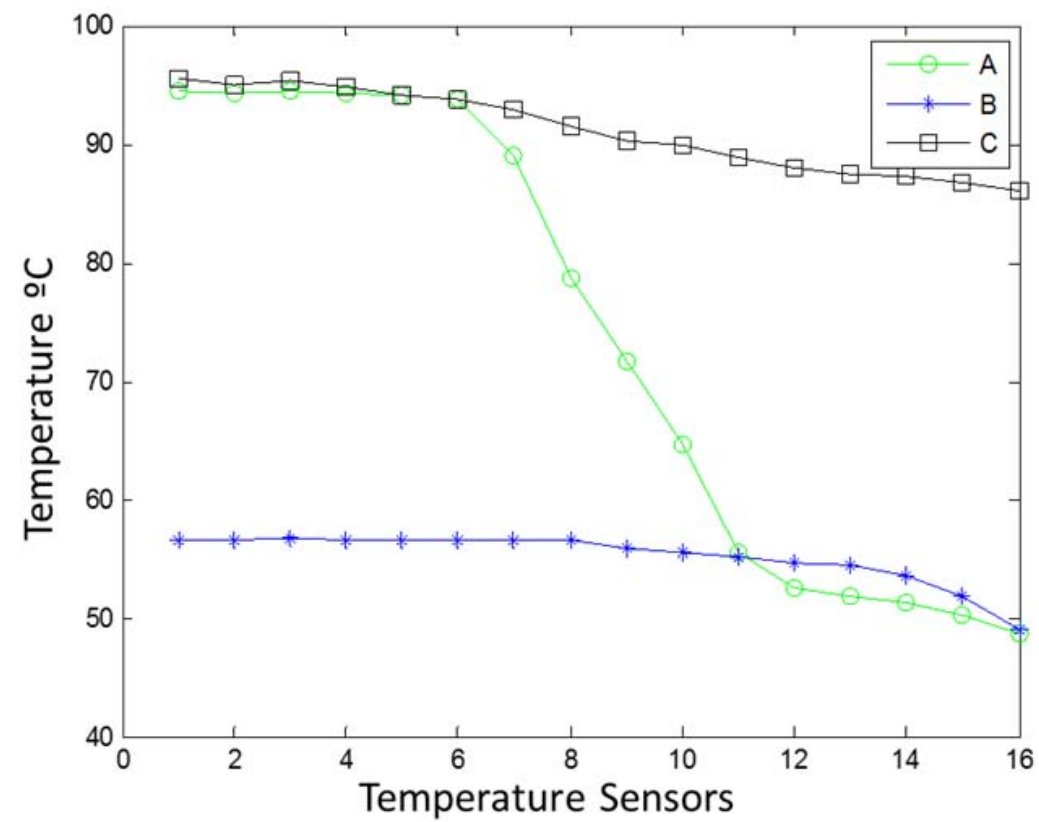

Fig. 8. Line (A) is the temperature across the tank when the water snake is used; while lines (B) and (C) are the temperatures without the water snake.

\subsection{Actual movement of the water snake}

Fig. 9 shows how clearly that the snake moves from one layer to another based on the supplied water temperature. Image A shows the water snake at the bottom of the tank where the supplied water is cold. Image B shows the water snake at the most top of the tank because the supplied water is at its hottest temperature level. Image $C$ shows the water snake while it moves down when slightly cooler water is supplied to settle in the middle layer of the tank as shown the image D. The images A to D in Fig. 9 are illustrated on the graph in Fig. 10. 

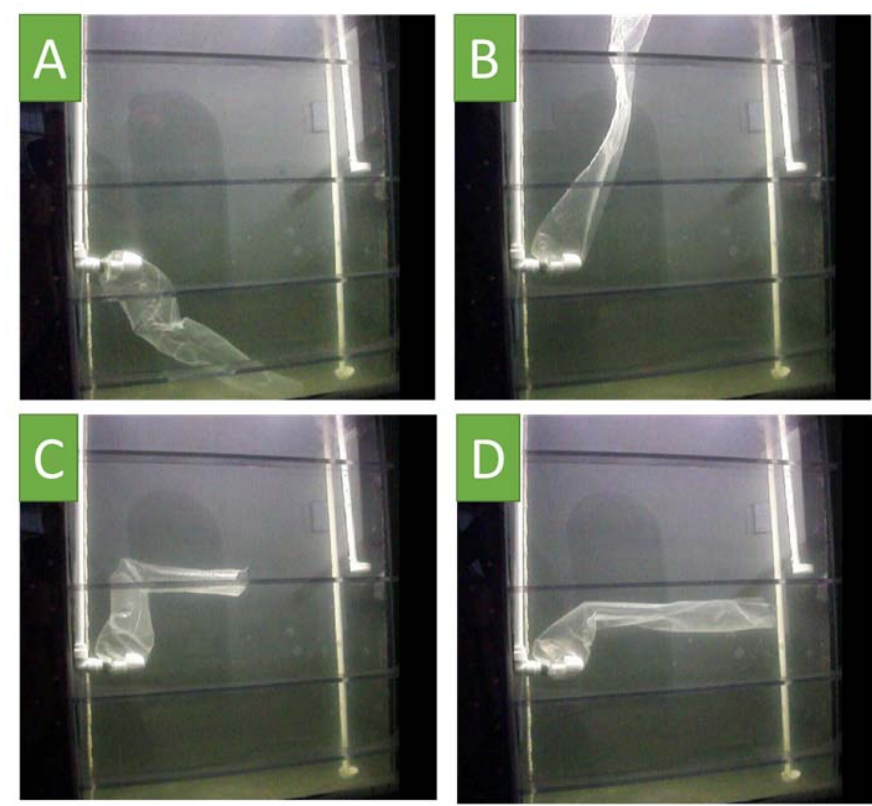

Fig. 9. Four images for the water snake in different positons during the experiment.

a

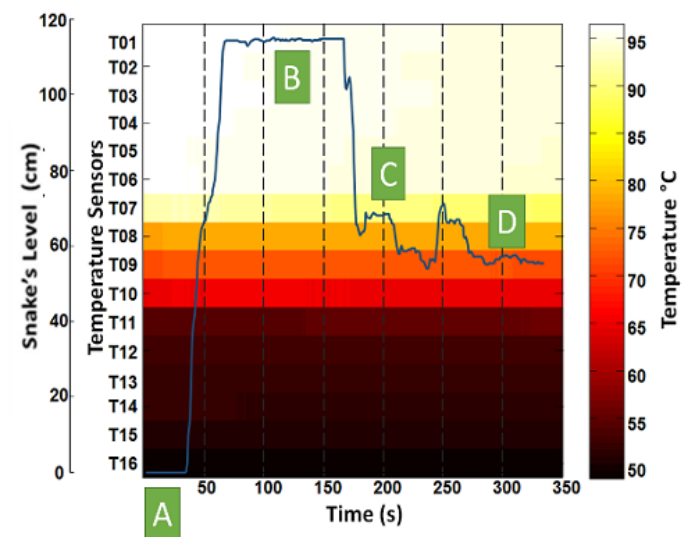

b

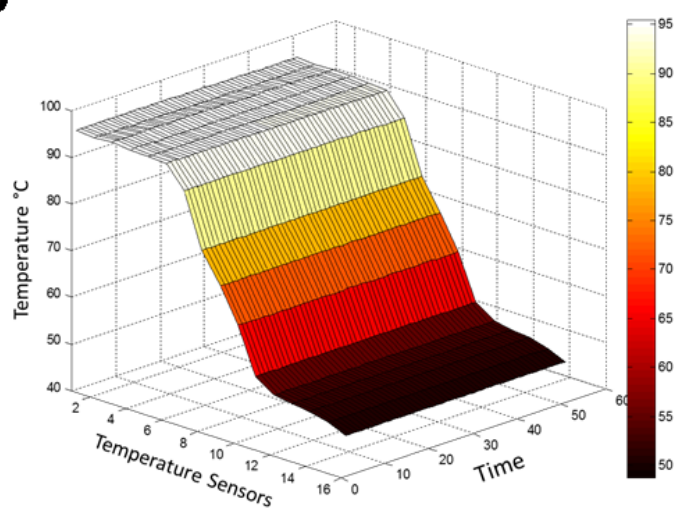

Fig. 10. The movement of the water snake inside a fully stratified tank (a); and a 3D representation for the stratification inside the tank after using the water snake (b).

Fig. 10-a is for the path (the blue line) drawn by intelligent code in Matlab for the snake's movement. This path represents the open end of the snake. The figure shows clearly how the water snake has led the supplied water to its correct destination layer that exactly matches with its temperature and density. This experiment started by supplying a cold water to the storage tank that was already stratified. The snake supplied the water to the bottom of the storage tank. See the label (A) in Fig. 10-a where the snake level at the bottom of the water tank. After that, a hot water of above $90{ }^{\circ} \mathrm{C}$ has been supplied to the 
storage tank. The water snake has immediately in few seconds moved up quickly to the highest level of the tank to supply that hot water to the top of the tank. This is denoted by label (B) in the Fig. 10-a. While the supply of the hot water continued for almost 120 seconds, the water snake stayed up there in stable condition. Once the supplied water changed to a colder water of about $75{ }^{\circ} \mathrm{C}$, the water snake moved quickly to the layer matched the same criteria as illustrated by label (C). Some turbulence in the snake movement can be noticed in this section however, the snake remained in that layer and at the end settled in it as it can be seen at Label (D). The stratification is clearly shown in the Fig. 10-b which is a 3D representation of the water temperature inside the tank. The temperature along the water tank have been measured by the sixteen sensors and found that after using the water snake the water kept well stratified by placing the hot water at the top and the cold water at the bottom without being mixed while it passes through other layers. Fig. 10-b shows the temperature measured along the tank (z-axis), the sixteen sensors (y-axis) and the time (x-axis).

\subsection{Stratification progress in One-hour experiment:}

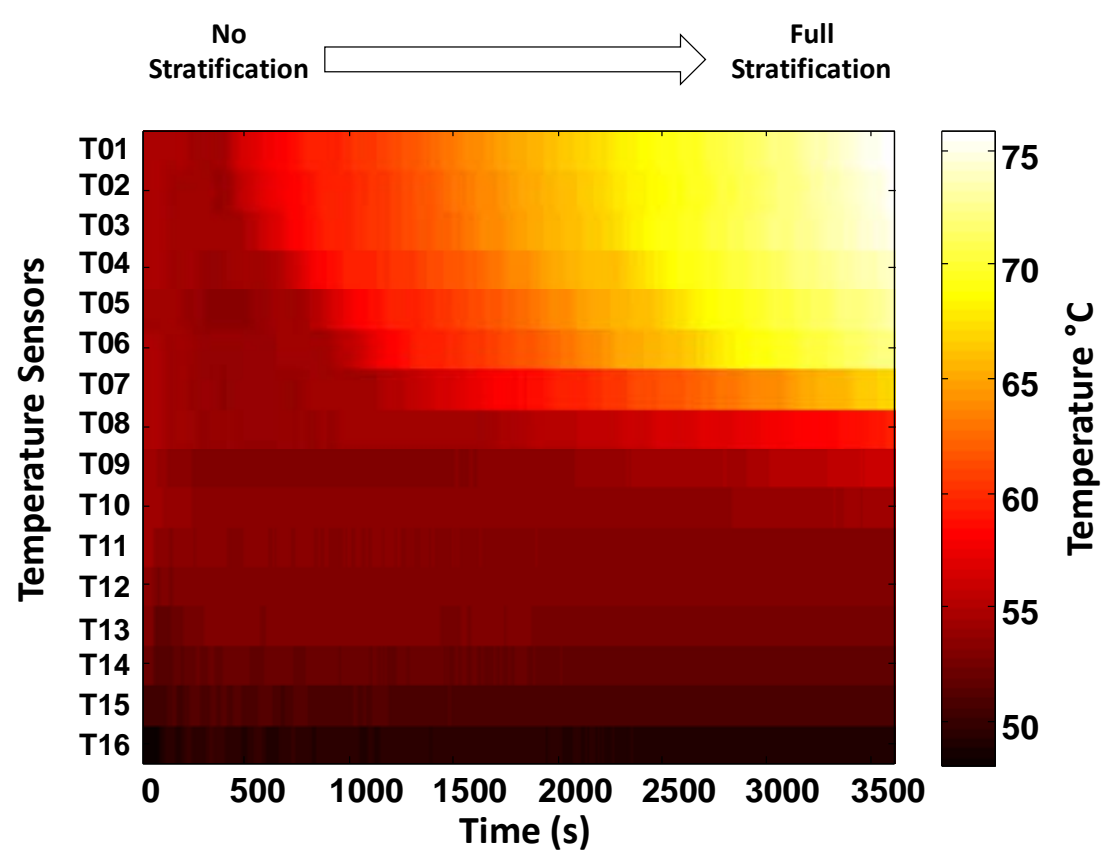

Fig. 11. The progress of the stratification in an hour using water snake.

Fig. 11 shows the records of the temperature across the height of the tank taken for one complete hour (3600 s) using the sixteen temperature sensors. The figure shows that the stratification process is successful using the water snake. As it can be seen in the figure, the first part, there was no stratification at all the temperature of the water in the tank ranged from 50 to $55{ }^{\circ} \mathrm{C}$. After few minutes, the stratification started to appear clearly, whereas, the water snake used to supply hot water to the tank. The water snake has 
supplied the hot water to the top despite its inlet was in the middle of the tank. There was no mixing, the tank ended up fully stratified, and the stored water temperature varied from 50 to $70^{\circ} \mathrm{C}$.

\subsection{Result confirmation experiment:}

One more experiment has been carried out to confirm the previous results. This time, the experiment ran for a longer time with changing the supplied water temperature. Fig. 12 shows the level of the water snake's movement inside the tank, which was full of cold water at the beginning. The path of the snake's movement has been detected using intelligent code in Matlab using image processing techniques. The path is shown in Fig. 12 in blue line above the background, which shows the temperature of the water along the experiment. The temperature of the water inside the tank was ranging from 20 to $25{ }^{\circ} \mathrm{C}$. The path of the water snake in Fig. 12 shows how fast the water snake can move from one layer to another when the supply water temperature changes.

The experiment has continued for more than three hours. During the experiment, the main events have been recorded. The sequence of events for the test were as follows in Table 1:

Table 1: The sequence of experimental events

\begin{tabular}{|c|c|}
\hline $\begin{array}{l}\text { Time } \\
\text { (s) }\end{array}$ & - Experiment events \\
\hline -- & $\begin{array}{l}\text { - Brief test to ensure the system including pump and heater stages were } \\
\text { working correctly. This put a little heat into the top of the tank. }\end{array}$ \\
\hline 0 & - Test started drawing water from the bottom of the tank. \\
\hline 0 & - Draw off point changed from the bottom to $800 \mathrm{~mm}$. \\
\hline 2500 & - System starts shutting off heaters as layer approaches its target of $70^{\circ} \mathrm{C}$. \\
\hline 5100 & $\begin{array}{l}\text { - Draw off point dropped to } 480 \mathrm{~mm} \text { with a new set point of } 45^{\circ} \mathrm{C} \text {, the three } \\
\text { heaters stages come on again. Snake drops }\end{array}$ \\
\hline-- & - The last heating stage drops out and the layer starts to stabilise. \\
\hline 6500 & $\begin{array}{l}\text { - The set point for the heating is set high to ensure the heating restarts and } \\
\text { all three stages remain on. The draw off point is changed back to } 800 \mathrm{~mm} \text {. } \\
\text { This causes the Snake to rise to the top again. }\end{array}$ \\
\hline 7000 & $\begin{array}{l}\text { - The draw off point is dropped back to } 480 \mathrm{~mm} \text { causing the snake to go } \\
\text { back to the lower position. }\end{array}$ \\
\hline
\end{tabular}




\begin{tabular}{|c|c|}
\hline 8500 & - The draw off point is raised to $800 \mathrm{~mm}$ again. Snake rises to top. \\
\hline 9500 & $\begin{array}{l}\text { - The draw off point is dropped to the bottom of the tank. Snake drops down } \\
\text { again. }\end{array}$ \\
\hline 10000 & - The draw off point is raised to $800 \mathrm{~mm}$ again. Snake rises to top. \\
\hline 11200 & $\begin{array}{l}\text { - The draw off point is dropped to the bottom of the tank and the target } \\
\text { progressively dropped to } 35^{\circ} \mathrm{C} \text {. The snake drops back down low again. }\end{array}$ \\
\hline-- & $\begin{array}{l}\text { - The last heat stage turns off leaving the pump to circulate without further } \\
\text { heat. }\end{array}$ \\
\hline-- & - The pump is stopped, the test has finished. \\
\hline
\end{tabular}

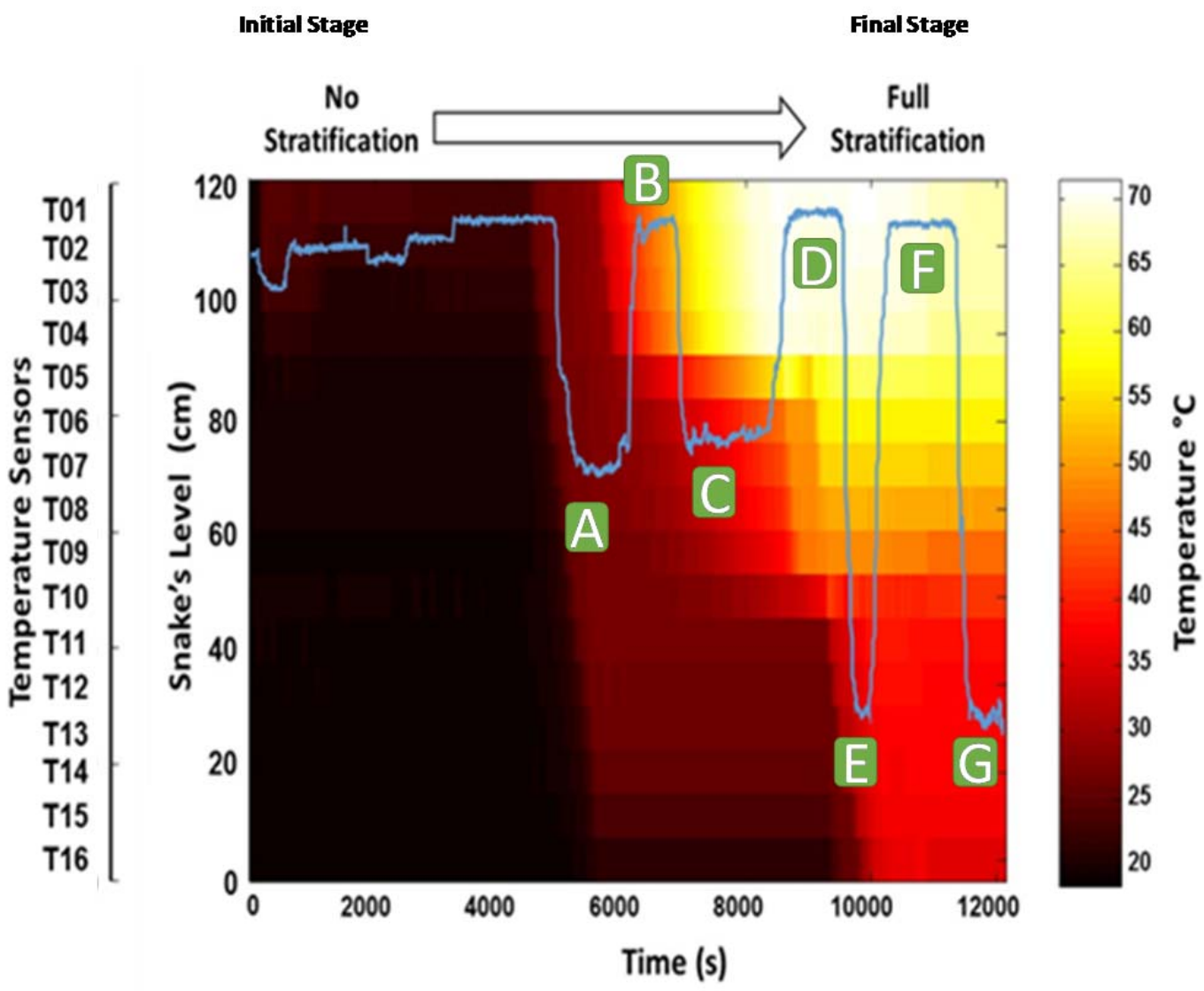

Fig. 12. The path of the water snake movement (the blue line) inside the tank as detected by intelligent code in Matlab. The background shows the temperature of the water as 
recorded by the 16 sensors against time. Fig. 12 shows how the water snake has led the water to its correct layer without affecting the stratification in the tank despite that water with different temperatures have been injected into tank in a random order. The points $\mathrm{A}$ to $G$ on the Fig. 12 show clearly that whenever hot water or cold water is injected the thank, the water snake will move to the right layer without disturbing the stratification in the tank. For example, the water snake has delivered hot water at point $\mathrm{D}$ then moved down to point E delivering cold water while the stratification remained perfectly which means no significant mixing.

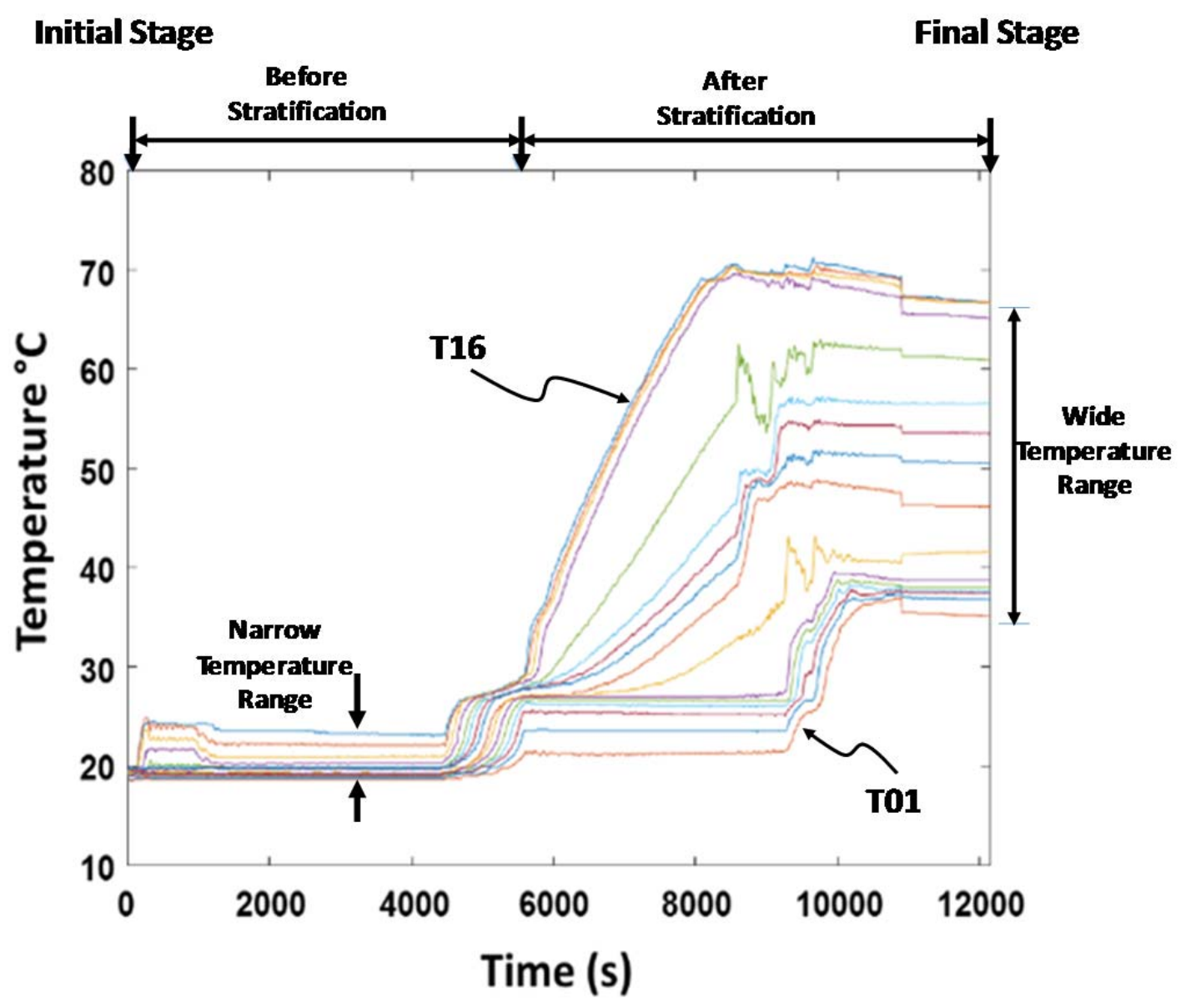

Fig. 13. The temperature profiles of the sixteen temperature sensors, T01- T16.

Fig. 13 shows the profile of the temperature for each sensor out of the sixteen temperature sensors used to record the temperature inside the tank. The figure shows clearly how the temperature of the water layers has widely variated after supplying water of different temperatures using the water snake. The water snake has significantly improved the stratification of the water inside the tank. The temperature inside the tank was ranging between 20 and $25{ }^{\circ} \mathrm{C}$ but after using the water snake it became ranging between 20 and $70{ }^{\circ} \mathrm{C}$ at some point then ranged from 30 to $70{ }^{\circ} \mathrm{C}$ after extra hot water entered the tank. 


\section{Thermal Images}

Thermal images of the front side of the tank have been taken using high-resolution thermal camera of $160 \times 120$ pixels and sensitivity of about $0.07{ }^{\circ} \mathrm{C}$. The images have shown a clear stratification of the tank after using the water snake. Fig. 14 presents two images throughout the experiment. Fig. 14-a shows image with low degree of stratification. Fig 14-b shows how the tank is fully stratified. The image shows the temperature of the tank is ranging from 20 to $70{ }^{\circ} \mathrm{C}$

a

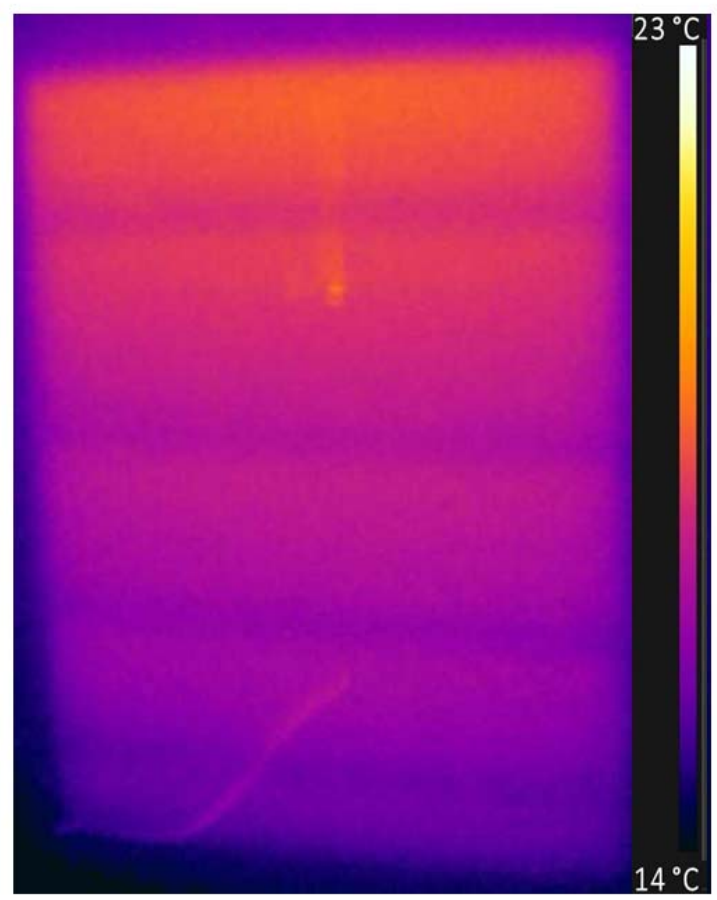

b

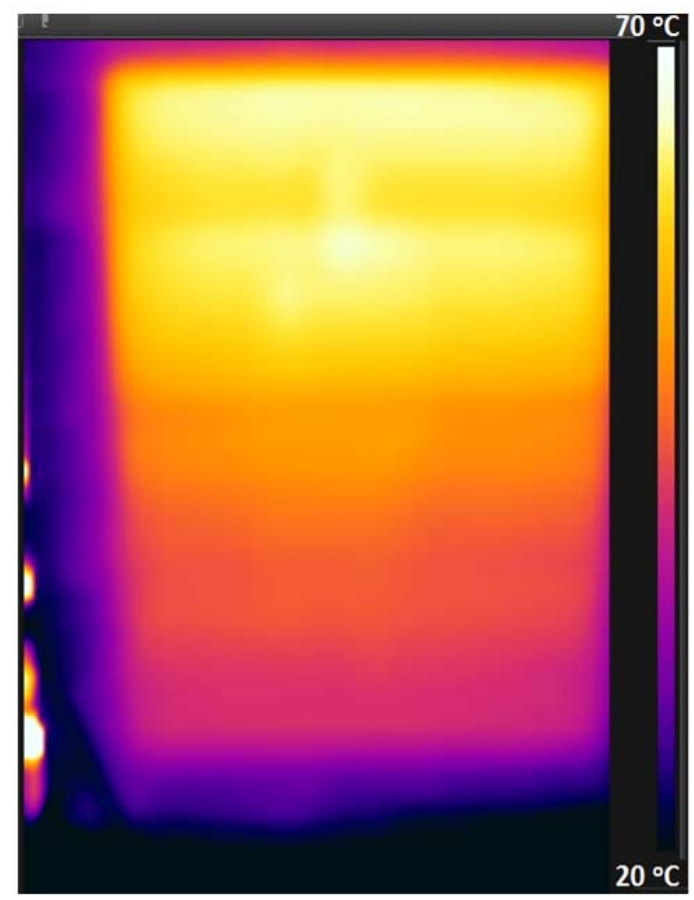

Fig. 14. Infrared thermal image of the fully stratified tank taken after using the water snake.

\section{Conclusion}

Stratification of water energy storage systems is currently attracting the attention of researchers and industry due to the need to improve energy efficiency and reduce running costs. Stratification has significant benefits for a wide range of systems including the ones that use a mixed-technology approach such as using a combination of solar energy, gas boilers, electric heaters and heat pumps. Also the technology could have a wider use in open loop systems for extracting energy from flooded coalmines and energy storage reservoirs. The use of flexible low density tube, the water snake, has been described in 
this paper. An automated system is used to test the capability of the technology. The use of the automated test rig has been found successful in evaluating the water snake technology. It has proved that the water snake is working perfectly in supplying the water to its exact layer that matches its temperature and density, hence achieving a high level of stratification.

\section{Limitations and Future Work}

Although this paper has experimentally presented the new concept of stratification and has proved its successful performance, several parameters and operational scenarios will need to be explored further. This includes in situ implementation with real supply and demand. Also long term assessment of the technology is still needed. Some parameters could also be investigated further such as the variation in water pressure and flow on the performance of the system. Based on the results of this paper, the actual implementation could also include more than one water snake within the same thermal storage, see Fig. 15. Future work will include the development and testing of the system in residential and commercial environments where different technologies for heating are integrated such as solar, thermal heat pump and boiler. It will also include carrying out experimental work on the same rig to evaluate the use of several water snakes in one tank. All fluid entering the vessel whether from a heat producer or a consumer should pass through a water snake. As an example, Fig. 15 shows a 3D representation of a thermal storage with three water snakes. In this case, the supply of water can be at different temperatures from different heat sources. Fig. 15-b shows the layers of different water temperatures and shows how the water snakes are settled in different layers. The use of different type material for the water snake and carrying out comparison to evaluate the best material that make the water snake performs better will also be investigated. The effect of the length of the water snake and the size of the tank will be investigated in the future for optimisation. In addition, the effect of turbulent flow on the water snake will be investigated. Finally, the use of the water snake in open loop energy systems from flooded coalmines will be investigated further to evaluate the suitability of the technology for such applications. 


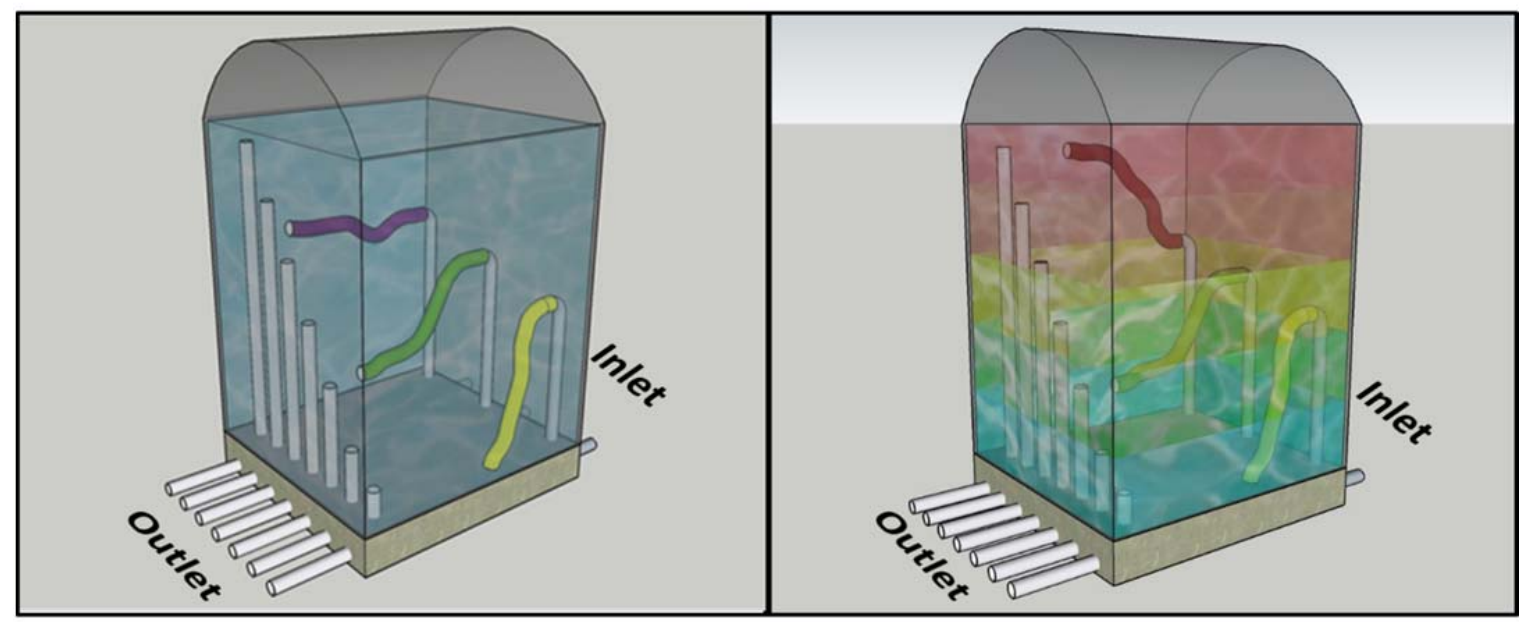

Fig. 15. 3D drawing of a multi water-snake tank (a) and presenting different layers of water at different temperatures (b).

\section{Acknowledgements}

This paper is based on research work partially carried out within the frame of research project: Low-Carbon After-Life (LoCAL) financed by the European Commission, Research Fund for Coal and Steel, July 2014-June 2017 (Contract No.: RFCR-CT-201400001). The development of the test rig is partially funded by Enabling Innovation, a European Regional Development Fund.

\section{Note:}

A short version of the paper was presented at ICAE2017, Aug 21-24, Cardiff, UK. This paper is a substantial extension of the short version of the conference paper [31].

\section{References:}

[1] C. Chang et al., "Comparative study of the transient natural convection in an underground water pit thermal storage,” Appl. Energy, vol. 208, no. April, pp. 1162-1173, 2017.

[2] M. W. Jack, K. Suomalainen, J. J. W. Dew, and D. Eyers, “A minimal simulation of the electricity demand of a domestic hot water cylinder for smart control," Appl. Energy, vol. 211, no. November 2017, pp. 104-112, 2018.

[3] A. G. Olabi, “Renewable energy and energy storage systems,” Energy, vol. 136, pp. 1-6, 2017.

[4] F. G. F. Qin et al., "Thermocline stability criterions in single-tanks of molten salt thermal energy storage,” Appl. Energy, vol. 97, pp. 816-821, 2012. 
[5] A. Mawire, "Experimental and simulated thermal stratification evaluation of an oil storage tank subjected to heat losses during charging," Appl. Energy, vol. 108, pp. 459-465, 2013.

[6] I. J. Moncho-Esteve, M. Gasque, P. González-Altozano, and G. Palau-Salvador, "Simple inlet devices and their influence on thermal stratification in a hot water storage tank,” Energy Build., vol. 150, pp. 625-638, 2017.

[7] R. M. Dickinson, C. A. Cruickshank, and S. J. Harrison, "Charge and discharge strategies for a multi-tank thermal energy storage,” Appl. Energy, vol. 109, pp. 366-373, 2013.

[8] S. Ievers and W. Lin, "Numerical simulation of three-dimensional flow dynamics in a hot water storage tank," Appl. Energy, vol. 86, no. 12, pp. 2604-2614, 2009.

[9] D. Zhou et al., “Technology Roadmap,” SpringerReference, vol. 92, no. January, p. 24, 2013.

[10] Q. Li et al., "Dynamic simulation and experimental validation of an open air receiver and a thermal energy storage system for solar thermal power plant," Appl. Energy, vol. 178, pp. 281-293, 2016.

[11] M. C. Rodríguez-Hidalgo, P. A. Rodríguez-Aumente, A. Lecuona, M. Legrand, and R. Ventas, "Domestic hot water consumption vs. solar thermal energy storage: The optimum size of the storage tank,” Appl. Energy, vol. 97, pp. 897-906, 2012.

[12] T. Bouhal, S. Fertahi, Y. Agrouaz, T. El Rhafiki, T. Kousksou, and A. Jamil, "Numerical modeling and optimization of thermal stratification in solar hot water storage tanks for domestic applications: CFD study,” Sol. Energy, vol. 157, no. August, pp. 441-455, 2017.

[13] A. P. Athresh, A. Al-Habaibeh, and K. Parker, "Innovative Approach for Heating of Buildings Using Water from a Flooded Coal Mine Through an Open Loop Based Single Shaft GSHP System,” Energy Procedia, vol. 75, no. 0, pp. 12211228, 2015.

[14] A. Al-Habaibeh, B. Meyerowitz, Duolan, and A. Athresh, “The Design and Development of an Innovative Simulator for an Open Loop System for Extracting Energy from Flooded Coal Mines,” Energy Procedia, vol. 75, no. 0, pp. 14701476, 2015.

[15] E. Palacios, D. M. Admiraal, J. D. Marcos, and M. Izquierdo, "Experimental analysis of solar thermal storage in a water tank with open side inlets," Appl. Energy, vol. 89, no. 1, pp. 401-412, 2012.

[16] S. Li, Y. Zhang, K. Zhang, X. Li, Y. Li, and X. Zhang, "Study on performance of storage tanks in solar water heater system in charge and discharge progress," Energy Procedia, vol. 48, pp. 384-393, 2014.

[17] S. Knudsen and S. Furbo, "Thermal stratification in vertical mantle heatexchangers with application to solar domestic hot-water systems," Appl. Energy, vol. 78, no. 3, pp. 257-272, 2004.

[18] C. Garnier, J. Currie, and T. Muneer, "Integrated collector storage solar water heater: Temperature stratification,” Appl. Energy, vol. 86, no. 9, pp. 1465-1469, 2009.

[19] Y. M. Han, R. Z. Wang, and Y. J. Dai, “Thermal stratification within the water 
tank,” Renew. Sustain. Energy Rev., vol. 13, no. 5, pp. 1014-1026, 2009.

[20] J. Fan, S. Furbo, and H. Yue, "Development of a Hot Water Tank Simulation Program with Improved Prediction of Thermal Stratification in the Tank,” Energy Procedia, vol. 70, pp. 193-202, 2015.

[21] E. Andersen, S. Furbo, and J. Fan, "Multilayer fabric stratification pipes for solar tanks,” Sol. Energy, vol. 81, no. 10, pp. 1219-1226, 2007.

[22] J. Bracamonte, J. Parada, J. Dimas, and M. Baritto, "Effect of the collector tilt angle on thermal efficiency and stratification of passive water in glass evacuated tube solar water heater,” Appl. Energy, vol. 155, pp. 648-659, 2015.

[23] J. Fernández-Seara, F. J. Uhía, Á. Á. Pardiñas, and S. Bastos, "Experimental analysis of an on demand external domestic hot water production system using four control strategies,” Appl. Energy, vol. 103, pp. 85-96, 2013.

[24] S. Wang and J. H. Davidson, "Performance of a rigid porous-tube stratification manifold in comparison to an inlet pipe," Sol. Energy, vol. 146, pp. 298-308, 2017.

[25] Vijay Dwivedi, “Thermal Modelling and Control of Domestic Hot Water Tank,” Thesis, no. 200858672, 2009.

[26] S. Wang and J. H. Davidson, "Selection of permeability for optimum performance of a porous tube thermal stratification manifold," Sol. Energy, vol. 122, pp. 472485, 2015.

[27] J. Dragsted, S. Furbo, M. Dannemand, and F. Bava, "Thermal stratification built up in hot water tank with different inlet stratifiers," Sol. Energy, vol. 147, pp. 414425, 2017.

[28] S. Fanshawe, A. Al-Habaibeh, and B. Shakmak, "An innovative design and evaluation of a stratified hot water storage system-the Water Snake,” 2015 IEEE Jordan Conf. Appl. Electr. Eng. Comput. Technol. AEECT 2015, pp. 1-6, 2015.

[29] C. A. Cruickshank and S. J. Harrison, "Heat loss characteristics for a typical solar domestic hot water storage,” Energy and Buildings, vol. 42, no. 10. pp. 17031710, 2010.

[30] M. Y. Haller, C. A. Cruickshank, W. Streicher, S. J. Harrison, E. Andersen, and S. Furbo, "Methods to determine stratification efficiency of thermal energy storage processes - Review and theoretical comparison,” Sol. Energy, vol. 83, no. 10, pp. 1847-1860, 2009.

[31] A. Al-habaibeh, B. Shakmak, and S. Fanshawe, “The development of an experimental test rig to evaluate the performance of a new technology for stratified hot water storage - The Water Snake,” ScienceDirect, vol. 00, no. August, pp. 2124, 2017. 